\title{
СОВЕРШЕНСТВОВАНИЕ ТЕХНИЧЕСКИХ СРЕДСТВ ПОДГОТОВКИ К СКАРМЛИВАНИЮ КЛУБНЕЙ КАРТОФЕЛЯ ЖИВОТНЫМ
}

\author{
V.V. Matyushev, I.A. Chaplygina,
} Yu.D. Shpiruk, O.V. Stenina

\section{THE IMPROVEMENT OF TECHNICAL MEANS OF PREPARATION FOR FEEDING ANIMALS WITH POTATOES TUBERS}

Матюшев В.В. - д-р техн. наук, проф., зав. каф.
товароведения и управления качеством продук-
ции АПК Красноярского государственного аграр-
ного университета, г. Красноярск.
E-mail: matyushe@yandex.ru
Чапльгина И.А. - канд. биол. наук, доц. каф.
товароведения и управления качеством продук-
ции АПК Красноярского государственного аграр-
ного университета, г. Красноярск.
E-mail: ledum_palustre@mail.ru
Шпирук Ю.Д. - соиск. каф. товароведения и
управления качеством продукции АПК Красно-
ярского государственного аграрного университе-
та, г. Красноярск.
Е-таil: matyushe@уаndех.гu
Стенина В.О. - соиск. каф. товароведения и управления качеством продукции АПК Красноярского государственного аграрного университета, г. Красноярск.

E-mail: matyushe@yandex.ru

Цель исследования - совершенствование технических средств, предназначенных для очистки клубнеплодов от почвенных загрязнений и дальнейшего измельчения картофреля 8 линии подготовки к скармливанию животньм в условиях фрермерских хозяйств, за счет оптимального сочетания комплекса конструктивных, технологических и режимных параметров установок. Описаны конструктивно-технологическая схема и принцип работы установок очистки от почвенных загрязнений и измельчения клубней картофеля. Экспериментальные исследования проводились на запатентованных установках. В исследовании были использованы клубни картофееля сорта Гала, которые по техническим требованиям не относятся к категориям «продовольственный»
Matyushev V.V. - Dr. Techn. Sci., Prof., Head, Chair of Merchandizing and Product Quality Control of AIC, Krasnoyarsk State Agrarian University, Krasnoyarsk.

E-mail: matyushe@yandex.ru

Chaplygina I.A. - Cand. Biol. Sci., Assoc. Prof., Chair of Merchandizing and Product Quality Control of AIC, Krasnoyarsk State Agrarian University, Krasnoyarsk.

E-mail: ledum_palustre@mail.ru

Shpiruk Yu.D. - Applicant, Chair of Merchandizing and Product Quality Control of AIC, Krasnoyarsk State Agrarian University, Krasnoyarsk. E-mail:

E-mail: matyushe@yandex.ru

Stenina V.O. - Applicant, Chair of Merchandizing and Product Quality Control of AIC, Krasnoyarsk State Agrarian University, Krasnoyarsk. E-mail:

E-mail: matyushe@yandex.ru

или «семенной» картофеель. При проведении исследования реализовывались матрицы пятифракторного эксперимента Бокса второго порядка по сухой очистке картофреля и четьрехфакторного эксперимента Бокса второго порядка для измельчения клубнеплодов. В качестве критериев оптимизации были выбраны: удельная энергоемкость процессов, эфрфективность очистки и качество измельчения клубней картофеля. На основании моделирования экспериментальных данных и оптимизации системы конструктивных, технологических показателей и режимных параметров очистки картофеля получены зависимости производительности установки при различных сочетаниях фракторов. На основании проведенных исследований было установлено, что оn- 
тимальными являются следующие фракторы: частота вращения рабочего стола - 450 мин $^{-1}$; длина, угол наклона и шаг установки лопаток - соответственно 77,3 мм, 16,2 град., 700 мм. При производительности 2,65 m/4 и удельной энергоемкости процесса очистки 1,05 кBm-4/m остаточная загрязненность не превышала 1,55 \%. В результате экспериментальных исследований определены эфрфективные показатели работы измельчителя клубней картофеля для птицы, свиней и крупного рогатого скота.

Ключевые слова: корнеклубнеплоды, картофель, мойка, установка, сухая очистка, измельчитель.

The aim of the research was to improve technical means intended for tubers cleaning from soil pollution and potato grinding in preparation for feeding animals due to optimal combination of the complex of structural, technological and operational parameters of plants. Structural and technological scheme and the principle of operation of the plant for cleaning from contamination and grinding of potato tubers were described. Experimental studies were conducted on patented installations. Gala potatoes, which on technical requirements do not respond to the categories "food" or "seed" potatoes were used. When carrying out the researches matrixes of five-factorial experiment of Box of the second order on cleaning potatoes and four-factorial experiment of Box of the second order for crushing tuber crops were realized. Specific energy intensity of the processes, the efficiency of cleaning and the quality of potato tubers grinding were chosen as optimization criteria. On the basis of experimental data of modeling and optimization of the design system, technological parameters and operating parameters of potato cleaning, the dependences of the plant performance for various combinations of factors were obtained. On the basis of conducted researches it was established that the following factors had been optimum: the frequency of rotation of the desktop - 450 min-1; the length, tilt angle and step of installation of shovels, respectively $77.3 \mathrm{~mm}, 16.2 \mathrm{deg}$., $700 \mathrm{~mm}$ with the productivity of $2.65 \mathrm{t} / \mathrm{h}$ and specific power consumption of the process of cleaning of $1.05 \mathrm{kWh} / \mathrm{t}$ residual impurity did not exceed $1.55 \%$. As the result of experimental studies, effective performance of potato tu- bers shredder for the poultry, pigs and cattle was determined.

Keywords: tubers, potatoes, washing, installation, dry cleaning, chopper.

Введение. В структуре себестоимости продукции животноводства корма занимают около 60-70 \% от всех затрат [1].

Для повышения продуктивности сельскохозяйственных животных в рацион вводятся сбалансированные кормовые смеси с применением корнеклубнеплодов (ККП).

Для подготовки корнеклубнеплодов к скармливанию животным предусмотрена их очистка от почвенных загрязнителей, так как они имеют загрязненность до 20 \% [2]. Для этих целей используются машины для мойки и сухой очистки корнеклубнеплодов от почвенных загрязнителей.

Недостатком применения операции мойки корнеклубнеплодов является большой расход воды, который создает проблемную ситуацию, особенно в зимнее время. В качестве недостатков в использовании конструкций для сухой очистки ККП следует отметить ненадежность оборудования в работе при несоблюдении необходимого качества очистки.

Поэтому в современных технологиях приготовления кормов заслуживает особого внимания разработка и внедрение ресурсо-энергосберегающего оборудования для сухой очистки корнеклубнеплодов от загрязнителей.

Другим препятствием на пути более широкого использования корнеклубнеплодов в животноводстве является высокая энергоемкость их измельчения, низкие качественные показатели готового продукта [3]. Поэтому проблема подготовки корнеклубнеплодов к скармливанию сельскохозяйственным животным является актуальной и представляет как научный, так и практический интерес. Формирование процессов одновременного резания и измельчения ККП является перспективным направлением для получения качественного корма.

Цель исследования: совершенствование технических средств очистки от почвенных загрязнений и измельчения клубней картофеля в линии подготовки к скармливанию животным, за счет оптимального сочетания комплекса конструктивных, технологических и режимных параметров установок. 
Задача исследования: определить оптимальные значения конструктивных и технологических режимных параметров функционирования установок по очистке от почвенных загрязнений и измельчения клубней картофреля в условиях фермерских хозяйств.

Методы исследования. Экспериментальные исследования проводились на запатентованных установках в Инжиниринговом центре ФГБОУ ВО и ООО "Учхоз "Миндерлинское"» ФГБОУ ВО Красноярский ГАУ (п. Борск, Сухобузимский район) в соответствии с действующими ГОСТами и общепринятыми методиками испытаний машин, обеспечивающих получение первичной информации с последующей их обра- боткой на ПЭВМ $[4,5]$. В исследованиях были использованы клубни картофреля сорта Гала, которые по техническим требованиям не относятся к категориям «продовольственный» или «семенной» картофрель (ГОСТ Р 51808-2013, ГОСТ Р 53136- 2008).

Результаты исследования и их обсуждение. Для подготовки клубней картофеля к скармливанию реализована технологическая схема: прием - сухая очистка от почвенных загрязнений - измельчение - выдача.

Схема технологической линии подготовки клубней картофеля к скармливанию представлена на рисунке 1.

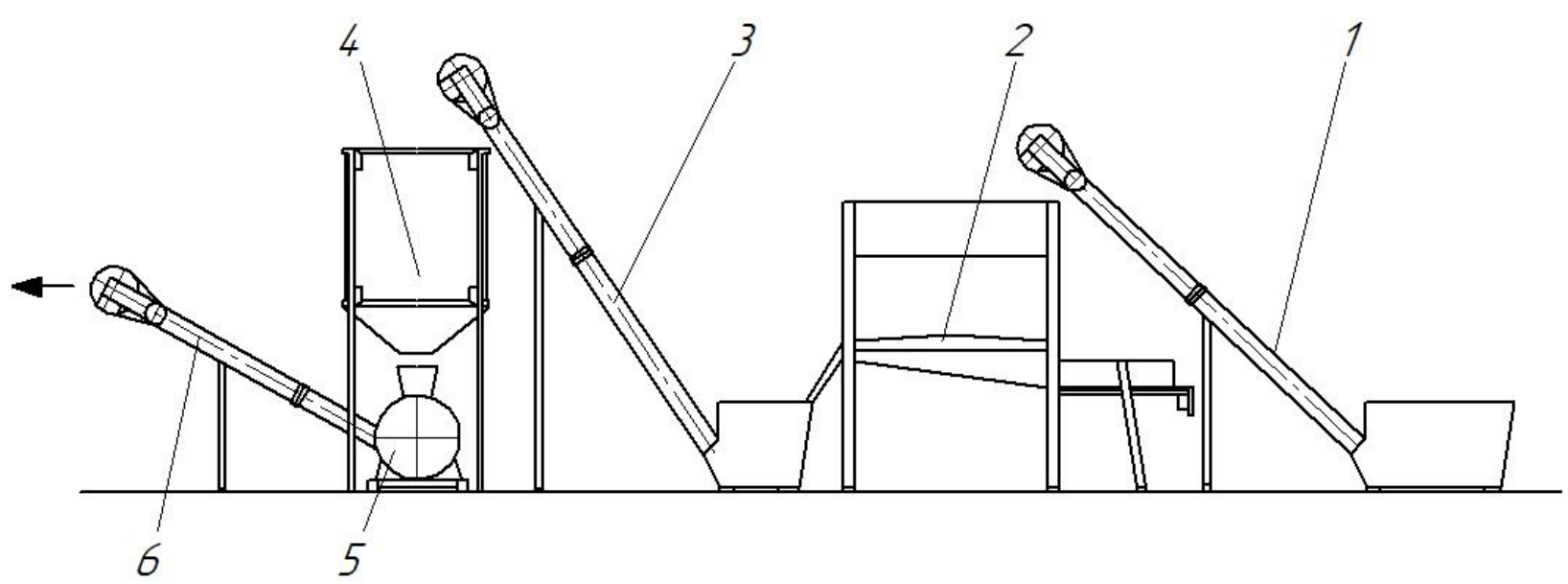

Рuc. 1. Схема технологической линии подготовки клубней картофеля

к скармливанию: 1, 3, 6 - транспортер; 2 - устройство для сухой очистки клубнеплодов; 4 - бункер-накопитель; 5 - измельчитель

Транспортером 1 клубни картофеля подаются в установку для ее сухой очистки. После прохождения между двумя пневмобаллонами и нарушения сцепления почвенных загрязнителей с картофелем материал поступает на вращающийся рабочий стол. Проходя по спирали и изменяя траекторию движения, за счет установленных на внутренней поверхности спирали лопаток картофель равномерно подвергается интенсивному механическому воздействию, дополнительно очищается от загрязнителей (рис. 2), поступает на транспортер 3, в бункернакопитель 4 (рис. 1, 2). Из бункера-накопителя картофель дозировано поступает в измельчитель 5. После измельчения картофель транспортируется на корм животным.

Общий вид измельчителя клубней картофреля представлен на рисунке 3.
В установке происходит предварительное резание клубней картофеля в рабочей зоне режущего органа, выполненного в виде набора ножей, установленных на конусном валу по образующей шнека, и окончательное измельчение ломтиков материала от их периферии к центру ножами измельчающего барабана.

При проведении исследований по сухой очистке картофеля реализовывалась матрица пятифракторного эксперимента Бокса второго порядка. В качестве факторов были выбраны: частота вращения рабочего стола $\left(\mathrm{x}_{1}\right)$, масса клубней картофреля $\left(\mathrm{x}_{2}\right)$; длина $\left(\mathrm{x}_{3}\right)$, угол наклона относительно витка спирали $\left(\mathrm{x}_{4}\right)$ и шаг установки лопаток $\left(x_{5}\right)$. Критериями оптимизации были эфффективность очистки клубней картофеля, удельная энергоемкость процесса. 
На основании моделирования экспериментальных данных и оптимизации системы конструктивных, технологических показателей и режимных параметров очистки картофреля получе- ны зависимости производительности установки при различных сочетаниях факторов на среднем уровне (рис. 4).

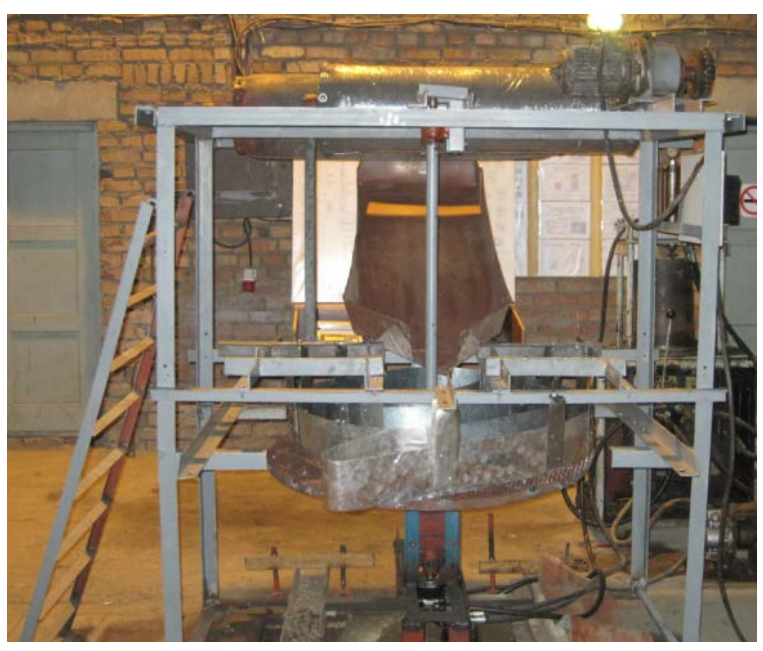

a

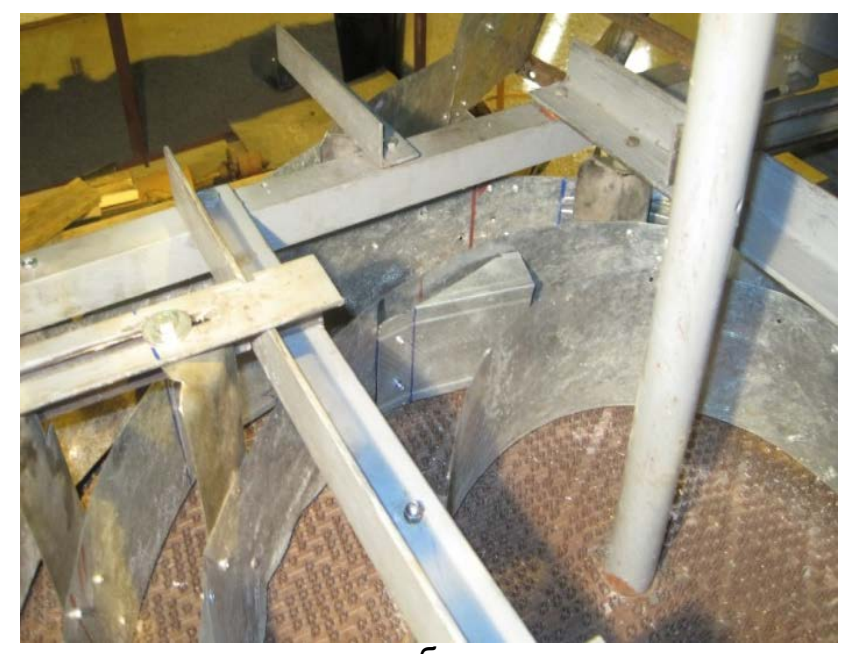

6

Puc. 2. Общий вид установки для сухой очистки картофеля (а) и установленных на спирали лопаток (б)

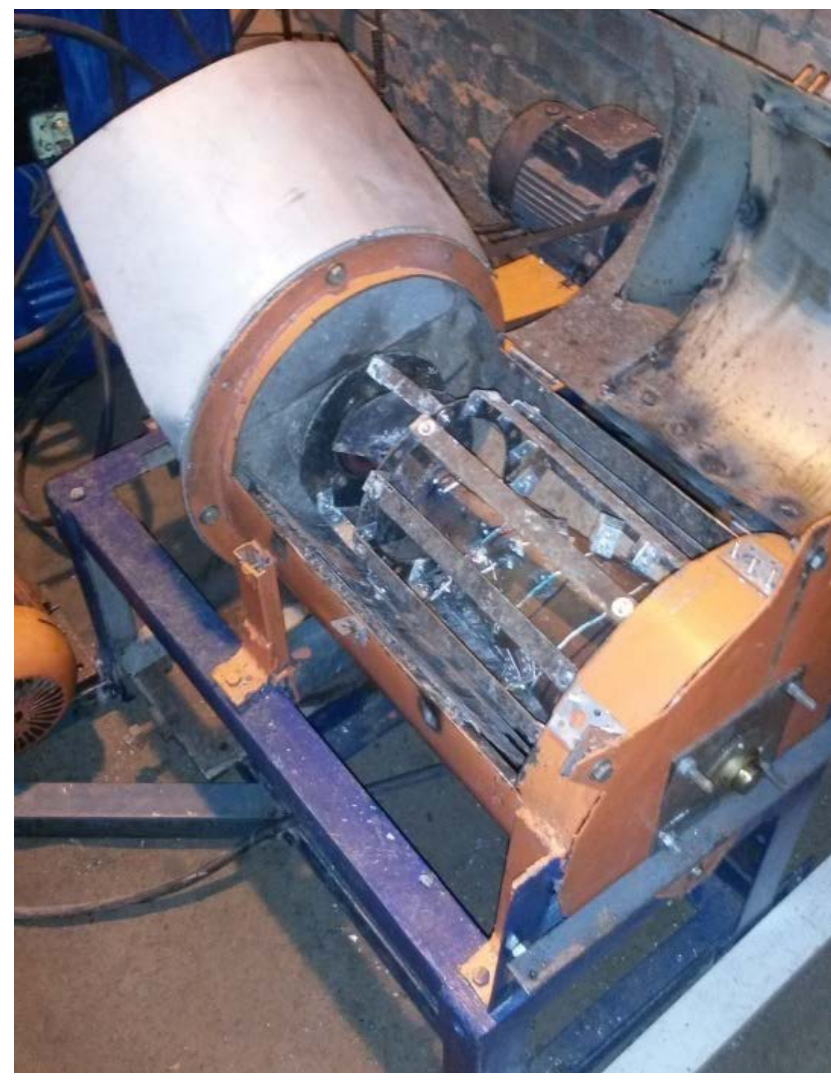

Puс. 3. Общий вид измельчителя клубней картофеля 


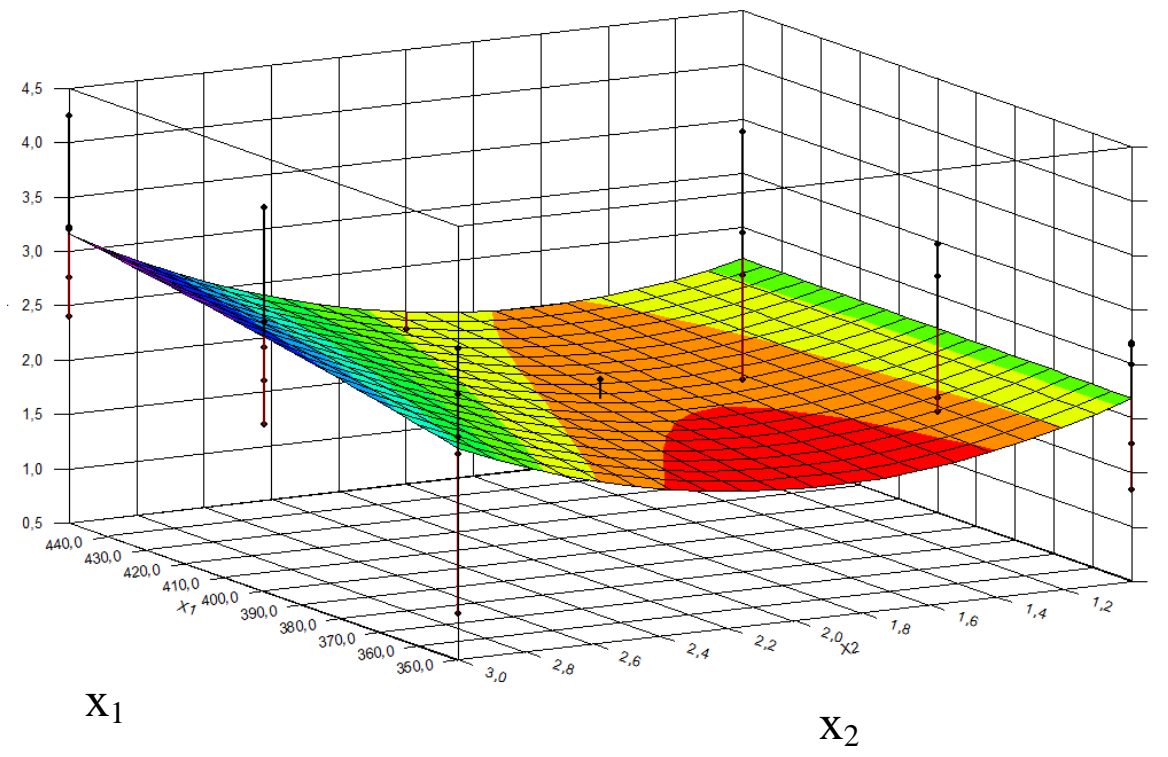

Puc. 4. Зависимость производительности установки от частоты вращения и массы клубней картофеля при усредненных значениях других фиксируемых показателей

На основании проведенных исследований было установлено, что оптимальными являются следующие факторы: частота вращения рабоче-

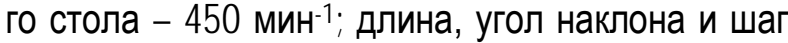
установки лопаток - соответственно 77,3 мм, 16,2 град., 700 мм. При производительности 2,65 т/ч и удельной энергоемкости процесса очистки 1,05 кВт-ч/т остаточная загрязненность не превышала $1,55 \%$.

Исходя из теоретических исследований и поисковых опытов, а также конструктивных параметров установки для измельчения клубней картофеля, были выбраны следующие факторы: частота вращения конусного вала $\left(\mathrm{x}_{1}\right)$ и измельчающего барабана масса $\left(\mathrm{x}_{2}\right)$; шаг установки ножей на конусном валу $\left(\mathrm{x}_{3}\right)$; угол наклона ножей барабана относительно горизонтальной оси $\left(\mathrm{x}_{4}\right)$.

Основными показателями для оценки оптимальной работы установки для измельчения картофеля служили качество измельчения клубней картофеля и удельная энергоемкость процесса.

В исследованиях реализовывалась матрица четырехфакторного эксперимента Бокса второго порядка.

В результате экспериментальных исследований определены эфффективные показатели работы установки.

Производительность и удельные энергозатраты на измельчение картофреля для птицы, свиней и крупного рогатого скота составили со- ответственно: $\quad 486,7-653,2 \quad \mathrm{k} / 4$ и $1,08-$ 1,29 Вт.ч/кг; 700,7-1047,0 кг/4 и 0,63-0,96 Вт.ч/кг; 1157,4-1469,9 кг/ч и 0,3-0,55 Вт.ч/кг.

В зависимости от толщины ломтика картофеля частота вращения конусного вала изме-

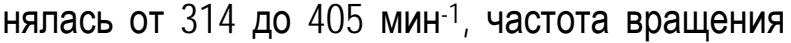
измельчающего барабана - от 368 до 419 мин $^{-1}$.

Шаг установки ножей на измельчающем барабане увеличивался от 33,0-42,2 мм (толщина ломтиков 1-4 мм) до 64,8-68,0 мм (толщина ломтиков 11-15 мм).

Угол наклона ножей на измельчающем барабане относительно горизонтальной оси изменялся от 2,76-10,2 град. (толщина ломтиков 14 мм) до 0,64-3,5 град. (толщина ломтиков 11$15 \mathrm{MM})$.

Выводы. Разработанные технические средства в технологической линии подготовки клубней картофеля к скармливанию непосредственно животным в условиях фермерских хозяйств могут использоваться также в составе линий производства экструдатов на основе зерна.

Остаточная загрязненность клубней картофреля (не более 1,55 \%) позволяет исключить их мойку перед измельчением.

Результаты исследования показывают перспективность применения установки для измельчения клубней картофреля в связи С возможностью ее использования для приготовления корма для птицы, свиней и крупного рогатого скота. 


\section{Литература}

1. Хохрин С.Н. Корма и кормление животных. СПб.: Лань, 2002. -512 c.

2. Механизация и технология производства продукции животноводства / В.Г. Коба, Н.В. Брагинеи, Д.Н. Мурусидзе, В.Ф. Некрашевич [и др.]. - М.: Колос, 2000. - 528 с.

3. Карташов Л.П., Юхин Г.П. О совершенствовании технологий заготовки, хранения и подготовки к скармливанию кормовых корнеплодов // Техника в сельском хозяйстве. - 2005. - № 1. - С. 42-43.

4. Пат. № 174584 Российская Федерация, МПК A01F 29/00. Измельчитель корнеклубнеплодов / Чапльгина И.А., Матюшев В.B., Семёнов А.В., Стенина В.О.; заявитель и патентообладатель ФГОУ ВПО «Красноярский ГАУ». - № 2016121327; заявл. 30.05.2016; опубл. 23.10.2017.

5. Пат. № 161769 Российская Федерация, МПК A01D 33/08. Устройство для сухой очистки корнеклубнеплодов / Шпирук Ю.Д., Матюшев В.В., Чапльгина И.А.; заявитель и патентообладатель ФГОУ ВПО «Красноярский ГАУ». - № 2015139018/13; заявл. 11.09.2015; опубл. 10.05.2016.

\section{Literatura}

1. Hohrin S.N. Korma i kormlenie zhivotnyh. SPb.: Lan', 2002. -512 s.

2. Mekhanizaciya i tekhnologiya proizvodstva produkcii zhivotnovodstva / V.G. Koba, N.V. Braginec, D.N. Murusidze, V.F. Nekrashevich [i dr.]. - M.: Kolos, 2000 - $528 \mathrm{~s}$.

3. Kartashov L.P., Yuhin G.P. O sovershenstvovanii tekhnologij zagotovki, hraneniya i podgotovki k skarmlivaniyu kormovyh korneplodov // Tekhnika v sel'skom hozyajstve. 2005. - № 1. - S. 42-43.

4. Pat. № 174584 Rossijskaya Federaciya, MPK A01F 29/00. Izmel'chitel' korneklubneplodov I Chaplygina I.A., Matyushev V.V., Semyonov A.V., Stenina V.O.; zayavitel' i patentoobladatel' FGOU VPO «Krasnoyarskij GAU». - № 2016121327; zayavl. 30.05.2016; opubl. 23.10.2017.

5. Pat. № 161769 Rossijskaya Federaciya, MPK A01D 33/08. Ustrojstvo dlya suhoj ochistki korneklubneplodov I Shpiruk Yu.D., Matyushev V.V., Chaplygina I.A.; Zayavitel' i patentoobladatel' FGOU VPO «Krasnoyarskij GAU». - № 2015139018/13; zayavl. 11.09.2015; opubl. 10.05.2016. 